\title{
Description of two anaerobic fungal strains from the bovine rumen and influence of diet on the fungal population in vivo
}

\author{
Vladimir A. Kostyukovsky, ${ }^{1 *}$ Oleg N. OKunev ${ }^{1}$ and Boris V. TaRaKanov ${ }^{2}$ \\ ${ }^{1}$ Laboratory of Microbial Physiology, Institute of Biochemistry and Physiology of Micro-organisms, USSR Academy of \\ Sciences, Pushchino, Moscow Region 142292, USSR \\ ${ }^{2}$ Laboratory of Animal Gut Microbiology, Institute of Animal Physiology, Biochemistry and Nutrition, Borovsk, \\ Kaluga Region 249010, USSR
}

(Received 15 February 1991; accepted 15 March 1991)

\begin{abstract}
Neocallimastix sp. NC71 and Piromyces sp. PC12 isolated from the calf rumen grew optimally at $39^{\circ} \mathrm{C}$ and pH 6.5-6.7, utilized a wide range of mono-, oligo- and polysaccharides and exhibited CMCase, Avicelase, cellobiase, amylase and xylanase activities. The end-products of wheat straw fermentation by both strains were acetate, formate, ethanol and lactate. The number of Neocallimastix sp. zoospores in the rumen of cows in the first $3 \mathrm{~h}$ after feeding with hay-silage-concentrate diets varied from $7 \times 10^{3}$ to $5.4 \times 10^{5} \mathrm{ml}^{-1}$; the number of uniflagellate zoospores varied from $10^{4}$ to $10^{5} \mathrm{ml}^{-1}$. Fungal zoosporogenesis and colonization of plant substrates in the rumen were induced by feed intake and were favoured by increased levels of crude fibre in the diet.
\end{abstract}

\section{Introduction}

The number of anaerobic fungi in the rumen is maximal in animals fed high-roughage diets, as in animals fed lowfibre rations the chytridiomycete population is reduced or absent (Bauchop, 1979). However, despite considerable interest in anaerobic fungi, information on their development in the rumen of animals receiving different diets is limited (Grenet et al., 1988). The contribution of the anaerobic mycoflora to feed digestion in the rumen has yet to be quantified.

The purpose of this work was to study morphological, physiological and biochemical properties of anaerobic fungi from the bovine rumen, and the isolation of chytridiomycetes from ruminants in the USSR is reported for the first time. The effect of different diets on the concentration of anaerobic fungal zoospores and the colonization of plant material in the bovine rumen was also investigated.

\section{Methods}

\begin{abstract}
Animals and diets. The fungi were isolated from the rumen of 5month-old rumen-fistulated calves fed a daily ratio of mixed cereal hay $(3 \mathrm{~kg})$ and concentrate $(3 \mathrm{~kg})$. The effects of different diets on the numbers of anaerobic fungi in the rumen were studied using four fistulated cows, each successively fed the following diets $\left(\mathrm{kg} \mathrm{d}^{-1}\right)$ : (I)
\end{abstract}

Abbreviation: VFA, volatile fatty acids. mixed cereal hay, 4.6; fodder beet, 24; corn silage, 20; energy concentrate, 8 ; (II) hay, 6 ; beet, 15 ; silage, 20 ; energy concentrate, 5 ; (III) hay, 8 ; beet, 10 ; silage, 20; energy concentrate, 5 ; (IV) wheat greens (harvested immediately before earing), 40; energy concentrate, 3. The rations were offered in two equal portions, at 8 am and $4 \mathrm{pm}$, for a $21 \mathrm{~d}$ period. Feeds were given separately, with 15 min intervals, in the following order: hay, silage, beet, concentrate. Refusals were collected after feeding and actual intakes were used for statistical analyses.

In period I (i.e. the time during which the animals received diet I), samples of rumen contents were taken $30 \mathrm{~min}$ before feeding and at $30 \mathrm{~min}$ intervals for $3 \mathrm{~h}$ after feeding. In periods II, III and IV the intervals between samples after feeding were $20 \mathrm{~min}$. The rumen contents were filtered through two layers of gauze and mixed $(1: 1)$ with $2 \%(w / v)$ formaldehyde solution. Zoospores were counted in a Goryayev haemocytometric chamber; genera were established using the descriptions of Orpin $(1975,1976,1977 a)$.

The extent of fungal colonization of the substrate was determined by incubating timothy hay in nylon bags in the rumen. Leaves were cut into $15-20 \mathrm{~mm}$ fragments and placed into $50-170 \mu \mathrm{m}$ porosity nylon bags ( 15 pieces per bag). The bags $(8 \times 7 \mathrm{~cm}$ in size) were tied to a $500 \mathrm{~mm}$ nylon cord and introduced through the fistula into the rumen just before feeding, and were incubated for $16 \mathrm{~h}$. After incubation, the bags were removed and washed with tap water. Leaf fragments were placed onto glass slides, dried with filter paper and stained for $50 \mathrm{~s}$ with lactophenol blue. The procedure (Akin, 1987) was modified by using methylene blue instead of trypan blue. Colonization was determined on five leaf fragments from each animal. The number of sporangia was counted microscopically in five arbitrarily selected areas of a leaf fragment. Chitin substances were stained by the method of Ravindranath \& Ravindranath (1975).

Isolation of anaerobic fungi. The primary isolation medium (Bauchop, 1979) contained $\left(1^{-1}\right)$ : main solution, $900 \mathrm{ml}$; reducing agents, $10 \mathrm{ml}$; $5 \%(\mathrm{w} / \mathrm{v}) \mathrm{K}_{2} \mathrm{HPO}_{4}, 10 \mathrm{ml}$; and $5.6 \%$ (w/v) $\mathrm{NaHCO}_{3}, 80 \mathrm{ml}$. The main 
solution consisted of $\left(\mathrm{NH}_{4}\right)_{2} \mathrm{SO}_{4}, 0.5 \mathrm{~g} ; \mathrm{KH}_{2} \mathrm{PO}_{4}, 0.5 \mathrm{~g} ; \mathrm{NaCl}, 1.0 \mathrm{~g}$; $\mathrm{MgSO}_{4} .7 \mathrm{H}_{2} \mathrm{O}, 0.05 \mathrm{~g} ; \mathrm{CaCl}_{2} .2 \mathrm{H}_{2} \mathrm{O}, 0.05 \mathrm{~g}$; peptone (Serva), $1.0 \mathrm{~g}$; yeast extract (Difco), $1.0 \mathrm{~g} ; 0.1 \%(\mathrm{w} / \mathrm{v})$ resazurin, $1 \mathrm{ml}$; clarified rumen fluid, $170 \mathrm{ml}$; distilled water to $900 \mathrm{ml}$ (Orpin, 1975). The reducing agents solution contained $2 \%(\mathrm{w} / \mathrm{v})$ cysteine. $\mathrm{HCl}$ and $1 \%(\mathrm{w} / \mathrm{v}) \mathrm{Na}_{2} \mathrm{~S}$ (Mountfort \& Asher, 1983). The substrates wheat straw (10 mg per $\mathrm{ml}$ medium) or filter paper $(8 \times 40 \mathrm{~mm}$ strip) were added to the tubes before sterilization. The main solution was deoxygenated by boiling and $9 \mathrm{ml}$ aliquots were dispensed anaerobically into culture tubes, which were sealed with butyl rubber stoppers (Bellco Glass). All solutions were sterilized separately by autoclaving $\left(121^{\circ} \mathrm{C}, 30 \mathrm{~min}\right)$. After sterilization, $\mathrm{K}_{2} \mathrm{HPO}_{4}(10 \mathrm{ml})$ and $\mathrm{NaHCO}_{3}(80 \mathrm{ml})$ solutions were mixed anaerobically and $0.9 \mathrm{ml}$ of the mixture and $0.1 \mathrm{ml}$ of reducing agents solution were injected into each tube. Immediately before inoculation, $0.1 \mathrm{ml}$ of a solution containing benzylpenicillin (sodium salt) and streptomycin sulphate was added into each test tube so that their concentrations in the medium were 1000 and $100 \mathrm{IU} \mathrm{ml}^{-1}$, respectively. Pure cultures of the anaerobic fungi were isolated in this medium supplemented with $2 \%(\mathrm{w} / \mathrm{v})$ agar and $0.2 \%(\mathrm{w} / \mathrm{v})$ cellobiose, using the method of Joblin (1979). Purity of the cultures was checked microscopically after inoculation into a liquid medium containing glucose without antibiotics (Lowe et al., 1985). The isolates were subcultured at intervals of $2-4 \mathrm{~d}$ with a $5 \%(\mathrm{v} / \mathrm{v})$ inoculum.

The fungi were also cultured on a semi-defined modification of the above medium in which the rumen fluid was replaced by solutions of volatile fatty acids (VFA, $10 \mathrm{ml})$, vitamins $(10 \mathrm{ml})$, trace elements $(10 \mathrm{ml})$, haemin $(10 \mathrm{ml})$ and distilled water $(130 \mathrm{ml})$. The VFA (Caldwell \& Bryant, 1966) did not include methyl butyrate. The vitamin solution was prepared as described by Lowe et al. (1985) and modified to contain biotin $\left(200 \mathrm{mg} \mathrm{l}^{-1}\right)$; niacin was used instead of nicotinamide and naphthoquinone was not included. The trace element solution contained (mg per $100 \mathrm{ml}$ ): $\mathrm{CaCl}_{2} .2 \mathrm{H}_{2} \mathrm{O}, 140 ; \mathrm{FeSO}_{4} .7 \mathrm{H}_{2} \mathrm{O}$, $250 ; \mathrm{MnSO}_{4} .5 \mathrm{H}_{2} \mathrm{O}, 220 ; \mathrm{ZnSO}_{4} .7 \mathrm{H}_{2} \mathrm{O}, 220 ; \mathrm{H}_{3} \mathrm{BO}_{4}, \quad 10 ;$ $\mathrm{Na}_{2} \mathrm{MoO}_{4} .2 \mathrm{H}_{2} \mathrm{O}, 15 ; \mathrm{Na}_{2} \mathrm{SeO}_{3}, 1.5 ; \mathrm{Na}_{2} \mathrm{SiO}_{3} .6 \mathrm{H}_{2} \mathrm{O}, 3.8 ; \mathrm{NH}_{4} \mathrm{VO}_{3}$, $1.2 ; \mathrm{KI}, 1.5 ; \mathrm{CuSO}_{4} .5 \mathrm{H}_{2} \mathrm{O}, 4 ; \mathrm{CoCl}_{2} .6 \mathrm{H}_{2} \mathrm{O}, 4 ; \mathrm{LiSO}_{4}, 0.8$; $\mathrm{NiCl}_{2} .6 \mathrm{H}_{2} \mathrm{O}, 0.4$; and $\mathrm{AlCl}_{3} \cdot 6 \mathrm{H}_{2} \mathrm{O}, 0.9$, as suggested for the cultivation of cellulolytic micromycetes (A. V. Shulga, unpublished data). The haemin $(0.1 \%)$ was dissolved in a $1: 1(\mathrm{v} / \mathrm{v})$ mixture of ethanol and $0.05 \mathrm{M}-\mathrm{NaOH}$. The trace element solution was added to the stock solution before sterilization. The haemin and VFA solutions were sterilized by autoclaving $\left(121^{\circ} \mathrm{C}, 30 \mathrm{~min}\right)$ and the vitamin solution was filter-sterilized. After sterilization, solutions of haemin $(10 \mathrm{ml})$, $\mathrm{NaHCO}_{3}(80 \mathrm{ml})$ and $\mathrm{K}_{2} \mathrm{HPO}_{4}(10 \mathrm{ml})$ were mixed anaerobically and the combined solution $(1 \mathrm{ml})$, vitamins $(0.1 \mathrm{ml})$, VFA $(0.1 \mathrm{ml})$ and reducing agents solution $(0.1 \mathrm{ml})$ were injected into tubes of sterile medium.

Morphological, physiological and biochemical properties. Morphology of the zoospores and thalli was studied by phase-contrast microscopy. The life cycle was studied in the semi-defined liquid medium containing cellobiose (Lowe et al., 1987b).

The ability of the strains to utilize various mono-, di- and polysaccharides was studied in a Yeast Nitrogen Base (YNB) medium (Difco), without antibiotics, prepared as follows: YNB $(6.7 \mathrm{~g})$ was mixed with VFA $(10 \mathrm{ml})$ and haemin solution $(10 \mathrm{ml}), \mathrm{K}_{2} \mathrm{HPO}_{4}(0.5 \mathrm{~g})$ and $\mathrm{NaHCO}_{3}(5 \mathrm{~g})$; the volume was adjusted to $100 \mathrm{ml}$ with distilled water. Test tubes were filled with $9 \mathrm{ml}$ boiled distilled water, sealed by butyl rubber stoppers, and autoclaved $\left(121^{\circ} \mathrm{C}, 30 \mathrm{~min}\right)$. Filtersterilized medium $(1 \mathrm{ml})$ and reducing agents solution $(0.1 \mathrm{ml})$ were injected into the tubes.

Temperature and $\mathrm{pH}$ optima for growth were determined by monitoring formate accumulation (Lowe et al., 1987a) after $3 \mathrm{~d}$ incubation in the semi-defined liquid medium with cellobiose at $27-$ $45^{\circ} \mathrm{C}$ and $\mathrm{pH} 4-8$.

Fermentation end-products were determined after 4-6 d growth in the semi-defined medium with either wheat straw, filter paper or cellobiose. VFA and ethanol were determined by gas chromatography; formate was estimated colorimetrically (Sleat \& Mah, 1984) and lactate enzymically (Noll, 1974).

The insoluble protein content of the fungal biomass in the cellobiosecontaining medium was determined after extraction with $1 \mathrm{M}-\mathrm{NaOH}$ at $100^{\circ} \mathrm{C}$ for $10 \mathrm{~min}$ (Pavlostathis et al., 1988).

Enzyme activities. Extracellular enzyme activities against carboxymethylcellulose (CMC), crystalline cellulose (Avicel), starch and xylan were determined by measuring liberated reducing sugars (Ghose $e t$ al., 1981). One unit of polysaccharidase activity released $1 \mu \mathrm{mol}$ of reducing sugar in $1 \mathrm{~min}$. Cellobiase activity was determined by measuring glucose release by the glucose oxidase method (Sherbuhin et al., 1970). One unit of cellobiase activity degraded $1 \mu \mathrm{mol}$ of substrate in $1 \mathrm{~min}$.

\section{Results}

\section{Characterization of strains isolated}

Two principal morphological types of fungi that differed in thallus form and size as well as in number of flagella and zoospore morphology were present. Cultures of anaerobic fungi with multiflagellate zoospores and with uniflagellate zoospores were isolated. One representative strain of each type, that grew well under the cultivation conditions used, was selected for detailed study.

\section{Morphology and life cycle of strain NC71}

The vegetative body was a branched septum-free colourless rhizoid that penetrated deeply into the plant tissue and reached $400 \mu \mathrm{m}$ in length and $10-15 \mu \mathrm{m}$ in thickness at the base. The thallus was monocentric. The zoosporangium formed on the surface of the substrate and was usually of ovoid or spherical form, $70-90 \mu \mathrm{m}$ in diameter. The colonies that formed in the agar medium in roll tubes were round and hyaline, up to $2 \mathrm{~mm}$ in diameter, with irregular edges. A cluster of up to 250 sporangia with radial mycelial hyphae was visible in the centre of the colony. The zoospores, 15-20 $\times 10-12 \mu \mathrm{m}$ in size, were oval, and possessed from 2 to $12(7 \pm 2$, $n=40$ ) flagella that were up to $40 \mu \mathrm{m}$ in length. Living zoospores were refractile.

Attachment to the inner walls of the culture tubes usually occurred in 1-2 h. The attached zoospore encysted and germinated; the flagella were usually, but not always, rejected. After $2-2.5 \mathrm{~h}$ the rhizoid was $40-$ $50 \mu \mathrm{m}$ in length. The main rhizoid then began to branch and grew rapidly up to a maximum rate of $30 \mu \mathrm{m} \mathrm{h}^{-1}$ by $15 \mathrm{~h}$ after inoculation. The sporangium growth rate during this period reached $24.8 \mu \mathrm{m} \mathrm{h}^{-1}$. Subsequently, the size of the rhizoid increased, mainly by the growth of side hyphae. The rhizoid ceased to grow by $18-20 \mathrm{~h}$ after inoculation. At this stage a partition was formed between 
Table 1. Principal end-products of substrate fermentation by strains NC71 and PC12

Composition of the fermentation end-products was determined after 4-6 d growth in the semi-defined medium with wheat straw, filter paper and cellobiose. The results are means \pm standard error $(n=4)$. Gaseous end-products were not determined.

\begin{tabular}{|c|c|c|c|c|c|c|c|c|}
\hline \multirow[b]{3}{*}{ Substrate } & \multicolumn{8}{|c|}{ Concentration of metabolite (mM) } \\
\hline & \multicolumn{2}{|c|}{ Acetate } & \multicolumn{2}{|c|}{ Formate } & \multicolumn{2}{|c|}{ Ethanol } & \multicolumn{2}{|c|}{ Lactate } \\
\hline & NC71 & $\mathrm{PC} 12$ & NC71 & $\mathrm{PC} 12$ & NC71 & $\mathrm{PC} 12$ & NC71 & $\mathrm{PC} 12$ \\
\hline Straw & $9 \cdot 8 \pm 2 \cdot 3$ & $10.9 \pm 0.9$ & $8 \cdot 0 \pm 0.2$ & $7 \cdot 0 \pm 1 \cdot 1$ & $6.5 \pm 0.6$ & $0.6 \pm 0.2$ & $1.0 \pm 0.4$ & 0 \\
\hline Paper & $13.4 \pm 8.2$ & $10 \cdot 2 \pm 2 \cdot 4$ & $12 \cdot 2 \pm 1 \cdot 7$ & $9 \cdot 0 \pm 3 \cdot 2$ & $8.9 \pm 0$ & $0 \cdot 3 \pm 0$ & $1 \cdot 5 \pm 1 \cdot 0$ & $0.01 \pm 0.02$ \\
\hline Cellobiose & $5 \cdot 3 \pm 0$ & $11 \cdot 0 \pm 3 \cdot 4$ & $4 \cdot 8 \pm 0 \cdot 1$ & $9.4 \pm 0.3$ & $4.8 \pm 0.1$ & $1 \cdot 2 \pm 0$ & $1 \cdot 1 \pm 0 \cdot 1$ & $0.01 \pm 0.02$ \\
\hline
\end{tabular}

Table 2. Activities of hydrolases produced by strains NC71 and PC12 in liquid semi-defined medium with wheat straw

Extracellular enzyme activities were measured in $3 \mathrm{~d}$ cultures and are expressed as nmol reducing sugars released $\min ^{-1}(\mathrm{ml} \text { culture })^{-1}$ for CMCase, Avicelase, amylase and xylanase or as nmol glucose produced $\min ^{-1}(\mathrm{ml} \text { culture })^{-1}$ for cellobiase. The results are means \pm standard error $(n=4)$.

\begin{tabular}{llllrl}
\hline \hline & \multicolumn{5}{c}{ Activity } \\
\cline { 2 - 6 } Strain & CMCase & Avicelase & Cellobiase & Amylase & Xylanase \\
\hline NC71 & $98 \pm 14$ & $3 \cdot 7 \pm 2 \cdot 1$ & $59 \pm 17 \cdot 0$ & $6 \cdot 7 \pm 1 \cdot 9$ & $398 \pm 38$ \\
PC12 & $36 \pm 10$ & $0 \cdot 6 \pm 0.3$ & $10 \pm 0.8$ & $12 \cdot 3 \pm 3 \cdot 9$ & $254 \pm 24$ \\
\hline \hline
\end{tabular}

it and the sporangium. After $20 \mathrm{~h}$, internal differentiation of the sporangium was apparent and its form changed from ovoid to spherical. After 24-26 h, the wall in the upper part of the sporangium broke and a new generation of zoospores was released into the external medium.

\section{Morphology and life cycle of strain PC12}

The rhizoid was septum-free and hyaline. The length of the main rhizoid ranged from 200 to $250 \mu \mathrm{m}$ and its thickness at the base was $6-8 \mu \mathrm{m}$. The thallus was monocentric, of the intramatrix type. The sporangium (up to $90 \mu \mathrm{m}$ in length) was cylindrical. Colonies in the agar medium in roll tubes were hyaline, $1-1.5 \mu \mathrm{m}$ in diameter, with irregular edges. The zoospores were oval and $10-12 \times 5-7 \mu \mathrm{m}$ in size. A single flagellum, 25$30 \mu \mathrm{m}$ in length, was usually present. Non-motile cells with two to five flagella sometimes occurred, probably due to disturbances in zoosporogenesis. When the zoospores ceased to move they became spherical. Within $1-2 \mathrm{~h}$ of inoculation the zoospores attached to the substrate, encysted and germinated. After attachment for $10 \mathrm{~h}$ the sporangium was $55-60 \mu \mathrm{m}$ in length; the thickness had increased insignificantly from 5 to $8 \mu \mathrm{m}$. After $18-20 \mathrm{~h}$, the thickness of the sporangium had reached $28-30 \mu \mathrm{m}$, a septum had formed between it and the rhizoid, and the internal differentiation of the zoospores had become noticeable. Liberation of the zoospores occurred $21-24 \mathrm{~h}$ after the release of the parent zoospore.

\section{Physiological and biochemical properties of the isolated strains}

Growth of strains $\mathrm{NC72}$ and $\mathrm{PC} 12$ was observed at 33$42^{\circ} \mathrm{C}$, and $\mathrm{pH} 6 \cdot 0-7 \cdot 0$, with optima at $39^{\circ} \mathrm{C}$ and $\mathrm{pH} 6 \cdot 5$ 6.7 respectively. Both strains were strictly anaerobic and unable to grow in liquid medium in the presence of air.

Both fungi grew well in liquid semi-defined media with wheat straw, timothy hay, filter paper, Avicel, soluble starch, xylan, D-glucose, D-xylose, D-lactose, D-maltose, D-sucrose or D-cellobiose as sole substrates. Fructose and melibiose were utilized poorly by NC71 and $\mathrm{PC} 12$ respectively. Growth of the strains was poor with $\mathrm{CMC}$ and pectin in both liquid and agar media in roll tubes. Polygalacturonic acid, aesculin, L-arabinose, D-galactose, lyxose, D-mannose, L-rhamnose, D-ribose, L-fucose, erythrose, dulcitol, $i$-inositol, D-mannitol, D-sorbitol, D-raffinose and D-trehalose were not assimilated.

The principal fermentation end-products of wheat straw, filter paper and cellobiose produced by strains $\mathrm{NC} 71$ and PC12 are presented in Table 1. Gaseous endproducts were not determined.

In the liquid semi-defined medium with wheat straw, strains NC71 and PC12 synthesized CMCase, Avicelase, cellobiase, amylase and xylanase. Extracellular activities of the enzymes in the culture supernatant after $3 \mathrm{~d}$ growth are given in Table 2. Temperature and $\mathrm{pH}$ optima for CMCase, cellobiase and xylanase were $50^{\circ} \mathrm{C}$ and $6 \cdot 0,50^{\circ} \mathrm{C}$ and $5 \cdot 5,45^{\circ} \mathrm{C}$ and 6.0 , respectively. 


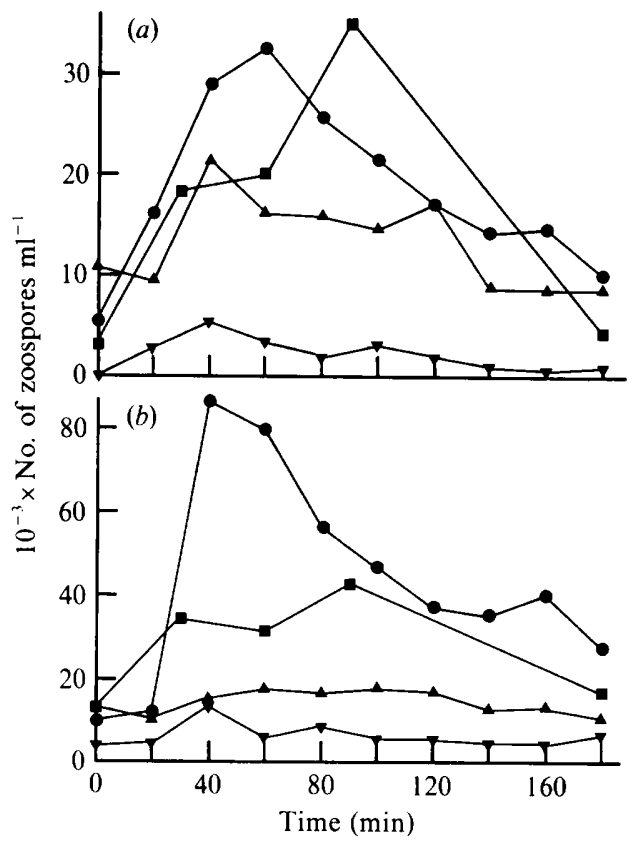

Fig. 1. Numbers of zoospores of (a) Neocallimastix and (b) Piromyces and Sphaeromonas (Caecomyces) in the initial $3 \mathrm{~h}$ of the postfeed period in cows fed one of four different rations: $\boldsymbol{\square}, \mathrm{I} ; \boldsymbol{\Lambda}, \mathrm{II} ; \boldsymbol{\bullet}, \mathrm{III} ; \boldsymbol{\nabla}, \mathrm{IV}$. Zoospore concentrations were determined in samples of rumen contents taken $30 \mathrm{~min}$ before feeding (zero point on the abscissa) and then at intervals of $30 \mathrm{~min}$ (period I) or $20 \mathrm{~min}$ (periods II, III and IV) for $3 \mathrm{~h}$ into the postprandial period.

Effect of diet on the anaerobic fungal population in the rumen

Uni- and multiflagellate zoospores of anaerobic fungi were found in the rumens of test animals fed all diets. The multiflagellate spores had an oval or round monad with granular cytoplasm and 2-15 flagella. The cell size varied from $12-20 \mu \mathrm{m}$. The number of multiflagellate zoospores observed in rumen fluid on diets I, II, III and IV was $7 \times 10^{3}-5.4 \times 10^{4} \mathrm{ml}^{-1}$. Two types of uniflagellate zoospores were detected, i.e. large round or oval (10$15 \mu \mathrm{m}$ in diameter) and small round $(3-8 \mu \mathrm{m})$. The ruminal population of these zoospores on diets I, II, III and IV was $10^{4}-10^{5} \mathrm{ml}^{-1}$. The multiflagellates were identified using morphological features, size and character of locomotion as reproductive cells of the fungus Neocallimastix sp. The uniflagellates were designated as zoospores of Sphaeromonas (syn. Caecomyces) and Piromyces spp. using the same criteria.

Before feeding, the concentration of all morphological types of zoospores was relatively low. After feeding, zoospore numbers increased significantly and were maximal after $90 \mathrm{~min}$ in period I and between 40 and $60 \mathrm{~min}$ in periods II, III and IV. By $3 \mathrm{~h}$ after feeding,
Table 3. Effect of diet on the fungal colonization of leaf material in the rumen

Sporangia were enumerated microscopically in five arbitrarily chosen areas of five leaf fragments from each animal. The results represent means \pm standard error $(n=25)$.

\begin{tabular}{|c|c|c|c|c|}
\hline \multirow[b]{3}{*}{ Animal } & \multicolumn{4}{|c|}{$10^{-3} \times$ Number of sporangia $\mathrm{cm}^{-2}$} \\
\hline & \multicolumn{4}{|c|}{ Diet and period: } \\
\hline & I & II & III & IV \\
\hline 1 & $7 \cdot 0 \pm 1 \cdot 7$ & $12 \cdot 0 \pm 1 \cdot 1$ & $18.4 \pm 1.7$ & $0 \cdot 11 \pm 0.04$ \\
\hline 2 & $10 \cdot 1 \pm 1 \cdot 0$ & $4.0 \pm 0.7$ & $15 \cdot 2 \pm 1 \cdot 2$ & $0.27 \pm 0.08$ \\
\hline 3 & $8.0 \pm 0.8$ & $4 \cdot 0 \pm 0 \cdot 4$ & $21 \cdot 7 \pm 2 \cdot 1$ & $0.52 \pm 0.15$ \\
\hline 4 & $3 \cdot 0 \pm 0 \cdot 3$ & $5 \cdot 1 \pm 0 \cdot 4$ & $13.2 \pm 1.6$ & $0.57 \pm 0.12$ \\
\hline
\end{tabular}

zoospore numbers in the rumen fluid had fallen to the initial level (Fig. 1 $a, b$ ). The number of zoospores was highest in the animals receiving the fibre-enriched diet III and was lowest in those fed pasture grass (diet IV).

Chitin-containing cylindrical, oval and fusiform bodies, identified as anaerobic fungal sporangia, were detected microscopically on the leaf surfaces after incubation in the rumen. Oval sporangia, $30-60 \mu \mathrm{m}$ in length, predominated. The cylindrical sporangia reached $60-90 \mu \mathrm{m}$ in length. The fusiform sporangia were the smallest $(<30 \mu \mathrm{m})$, and probably represented immature forms of the other zoosporangia types. The sporangium surface was rough. Some preparations had distinct smooth hyaline rhizoids up to $10 \mu \mathrm{m}$ thick that originated from the base of the sporangium. Fungal thalli were mostly attached to leaf veins. The extent of colonization varied with diet and correlated positively with the proportion of hay in the ration $(r=0.82$, $P<0.01)$ and negatively with the quantity of beet $(r=-0.67, P<0.05)$. When the animals were fed the maximal amount of hay and the minimal amount of beet (in diet III), the number of sporangia on the leaf surface reached $1.7 \times 10^{4} \mathrm{~cm}^{-2}$, which was 2.5 times as high as with diet I (Table 3).

\section{Discussion}

The strains isolated differed in thallus and zoospore morphology, the composition and ratio of fermentation end-products and the level of extracellular enzyme activities. Using these features, strains $\mathrm{NC} 71$ and $\mathrm{PC} 12$ were assigned to the Chytridiomycete genera Neocallimastix and Piromyces, respectively. Neocallimastix sp. NC71 had similar zoospore morphology to $N$. frontalis (Heath et al., 1983) and N. patriciarum (Orpin \& Munn, 1986) but differed from these Neocallimastix spp. in the 
proportion of the main fermentation end-products formed from various substrates (Phillips \& Gordon, 1988; Breton et al., 1989).

Strain PC12 was similar to Piromyces communis (Orpin, 1977a) but differed as it could use both sucrose and melibiose for growth, and was unable to utilize raffinose. This is the first description of a strain of Piromyces that is able to grow on melibiose (Phillips \& Gordon, 1988). Strain PC12 also differed from other strains of Piromyces sp. that have been isolated (Fonty et $a l ., 1988)$ in its zoospore morphology and in the nature and ratio of the main fermentation end-products. The paucity of detailed information on the physiological and biochemical properties of Piromyces sp. precluded the assignment of strain $\mathrm{PC} 12$ to a definitive species.

The marked increase in the concentration of zoospores of anaerobic fungi from the genera Neocallimastix, Sphaeromonas (Caecomyces) and Piromyces in rumen fluid in the first hour after feeding has been reported previously and highlights the dependence of the induction of zoosporogenesis on feed intake (Orpin, 1977b; Bauchop, 1979). The delayed release of zoospores in animals receiving diet I (high in concentrates) may have been due to this low-roughage ration being deficient in plant-associated inducers of zoosporogenesis (Orpin, 1977b).

In our experiments the concentration of zoospores in the rumen fluid and extent of colonization of timothy leaves were maximal when the animals were fed the high-roughage diet (III) and were minimal when they were fed diet IV. Although the experiments continued over a 12-week period and seasonal variations in the populations may have occurred, the observed differences are more likely to be due to diet effects, as reported by Bauchop (1979, 1981) and Grenet et al. (1988). In period II, with an increased proportion of hay and decreased concentrate and beet in the diet, a fall in the zoospore numbers and the extent of colonization of timothy leaves was observed in two of the four animals under study. However, the correlation analysis confirmed the dependence of the extent of colonization in the rumen on the proportion of hay and beet in the diet.

As zoospore concentration in filtered rumen fluid is not a reliable marker of the biomass and metabolic activity of anaerobic fungi in the rumen (Bauchop, 1979), a better estimate may be obtained by determining the extent of fungal colonization of the substrate in nylon bags in situ.

\section{References}

AKIN, D. E. (1987). Association of rumen fungi with various forage grasses. Animal Feed Science and Technology 16, 273-285.
BauCHOP, T. (1979). Rumen anaerobic fungi of cattle and sheep. Applied and Environmental Microbiology 38, 148-158.

BAUCHOP, T. (1981). The anaerobic fungi in rumen fibre degradation. Agriculture and Environment 6, 339-348.

Breton, A., Bernalier, A., Bonnemoy, F., Fonty, G., Gaillard, B. \& GoUET, P. (1989). Morphological and metabolic characterization of the strictly anaerobic rumen fungus Neocallimastix joyonii. FEMS Microbiology Letters 58, 309-314.

Caldwell, D. R. \& BRYANT, M. P. (1966). Medium without rumen fluid for non-selective enumeration and isolation of rumen bacteria. Applied and Environmental Microbiology 14, 794-801.

Fonty, G., Gouet, Ph. \& SanTe, V. (1988). Influence d'une bactérie méthanogène sur l'activité cellulolitique et la métabolisme de deux espèces de champignons cellulolytiques du rumen in vitro. Résultats préliminaires. Reproduction, Nutrition, Développement 28, 133134.

Ghose, T., Montenecourt, B. S. \& Eveleigh, D. E. (1981). In Measurement of Cellulase Activity, p. 72. IUPAC Commission on Biotechnology.

Grenet, E., Breton, A., Fonty, G. \& Rémond, B. (1988). Influence du régime alimentaire sur la population fongique anaérobie du rumen. Reproduction, Nutrition, Développement 28, 127-128.

Heath, I. B., Bauchop, T. \& ScIPp, R. A. (1983). Assignment of the rumen anaerobe Neocallimastix frontalis to the Spizellomycetales (Chytridiomycetes) on the basis of its polyflagellate zoospore ultrastructure. Canadian Journal of Botany 61, 295-307.

JOBLIN, K. (1979). Isolation, enumeration and maintenance of rumen anaerobic fungi in roll tubes. Applied and Environmental Microbiology 42, $1119-1122$.

Lowe, S. E., Theodorou, M. K., Trinci, A. P. J. \& Hespell, R. B. (1985). Growth of anaerobic rumen fungi on defined and semidefined media lacking rumen fluid. Journal of General Microbiology 131, 2225-2229.

Lowe, S. E., Griffith, G. G., Milne, A., Theodorou, M. K. \& TRINCI, A. P. J. (1987a). The life cycle and growth kinetics of an anaerobic rumen fungus. Journal of General Microbiology 133, 18151827.

Lowe, S. E., Theodorou, M. K. \& Trinci, A. P. J. (1987b). Cellulases and xylanase of an anaerobic rumen fungus grown on wheat straw, wheat straw holocellulose, cellulose and xylan. Applied and Environmental Microbiology 53, 1216-1223.

MOUNTFORT, D. O. \& ASHER, A. (1983). Role of catabolite regulatory mechanisms in control of carbohydrate utilization by the rumen anaerobic fungus Neocallimastix frontalis. Applied and Environmental Microbiology 46, 1331-1338.

NOLL, F. (1974). L-(+)-Lactate determination wth LDH, GPT and NAD. In Methods of Enzymatic Analysis, 2nd edn, pp. 1475-1479. (Transl. from 3rd German ed.). Edited by H. U. Bergmeyer. Weinheim: Verlag Chemie.

ORPIN, C. G. (1975). Studies on the rumen flagellate Neocallimastix frontalis. Journal of General Microbiology 91, 249-262.

ORPIN, C. G. (1976). Studies on the rumen flagellate Sphaeromonas communis. Journal of General Microbiology 94, 270-280.

ORPIN, C. G. (1977a). The rumen flagellate Piromonas communis: its life-history and invasion of plant material in the rumen. Journal of General Microbiology 99, 107-117.

OrPIN, C. G. $(1977 b)$. On the induction of zoosporogenesis in the rumen phycomycetes Neocallimastix frontalis. Piromonas communis and Sphaeromonas communis. Journal of General Microbiology 101, 181-189.

OrPIN, C. G. \& MunN, E. A. (1986). Neocallimastix patriciarum sp. nov., a new member of the Neocallimasticaceae inhabiting the rumen of sheep. Transactions of British Mycological Society 86, 178-181.

Pavlostathis, S. G., Miller, T. R. \& Wolin, M. J. (1988). Fermentation of insoluble cellulose by continuous cultures of Ruminococcus albus. Applied and Environmental Microbiology 54, 2655-2659.

Phillips, M. W. \& Gordon, L. R. (1988). Sugar and polysaccharide fermentation by rumen anaerobic fungi from Australia, Britain and New Zealand. BioSystems 21, 377-383. 
RavindRanath, R. M. H. \& RavindRanath, M. H. (1975). A simple procedure to detect chitin in delicate structures. Acta Histochemica 53, 203-205.

Sherbuhin, V. D., Mironova, L. I., Kondyreva, A. V. \& Gunter, V. S. (1970). Determination of glucose in molasses by the glucose oxidase method using potassium ferrocyanide. Applied Biochemistry and Microbiology 6, 467-470.

SLEAT, R. \& MAH, R. A. (1984). Quantitative method for colorimetric determination of formate in fermentation media. Applied and Environmental Microbiology 47, 884-885. 